\title{
Faces of Risk and Resilience: Fathers and Their Families
}

\author{
Rob Palkovitz ${ }^{1}$ (D) Jay Fagan ${ }^{2}$
}

Accepted: 1 March 2021 / Published online: 19 March 2021

(C) Springer Nature Switzerland AG 2021

\begin{abstract}
The global Covid-19 pandemic and heightened focus on systemic racism in the USA provide differential lenses for considering contexts of risk and resilience as they apply to individual fathers and their families. Intersections of race, class, culture, personal characteristics, and access to resources uniquely shape fathers' resilience as they navigate risks to themselves and their families. The interdependence of families with other community members, family work, role enactments, gender, and policy highlights the centrality of fathers' executive function in conjunction with available resources to shape the quality of individual father-child relationships and the overall wellbeing of fathers and their families. This commentary focuses on the current pandemic and racism as risk factors for families, the ways in which fathers are uniquely affected by these risks, the ways in which fathers exhibit resilience in the face of these adversities, and implications for future research about the ways in which fathers' gendered behaviors and attitudes may ultimately change as a consequence of the pandemic and systemic racism.
\end{abstract}

Keywords Fathering $\cdot$ Risk $\cdot$ Resilience $\cdot$ Executive function $\cdot$ Resources $\cdot$ Policy $\cdot$ Intersectionality

Risk has become pervasive in the lives of all people resulting from the global Covid-19 pandemic and recent attention to systemic racism. Whereas risk tended to be relegated to specific sub-groups of the population, essentially everyone on all seven continents of the earth is faced with new levels of potential risk now.

\section{Pervasiveness of Risk Due to the Pandemic and Systemic Racism}

In the past, the risk and resilience perspective has largely been applied to at-risk populations in contexts such as child welfare, poverty, low-income communities, and unemployment. However, unprecedented contemporary conditions in both national and global contexts have been especially challenging for a considerably broader range of families and their children as they consider potentially life-threatening issues regarding health and safety. Whole sectors of the population, who were previously perceived to be outside of the category of "at risk

Rob Palkovitz

robp@udel.edu

1 University of Delaware, Newark, Delaware, USA

2 Temple University, Philadelphia, PA, USA individuals," have needed to increase vigilance regarding health and social issues with potentially serious consequences. Specifically, recent events surrounding the Covid-19 pandemic and, in the USA, those associated with systemic racism and police activity have caused many people in previously insulated social addresses to heighten awareness as they consider or reconsider issues of risk, adversity, and resilience. Covid19 has precipitated global changes in health, social interaction, economics, travel, education, and countless other spheres, placing billions of individuals at risk. By contrast, systemic racism in America has a less universal impact than Covid-19, but its consequences are no less life-altering and lifethreatening for those it touches. Further, the risks of Covid-19 interact with race: Black and Brown Americans have suffered higher infection and mortality rates from Covid-19 in comparison to Whites (American Medical Association, 2020), and the BBC has reported that globally, Black people are more than two times as likely and Asian people are 1.5 times as likely as White people to be infected (Mundasad, 2020). The interaction of health outcomes and race can be partially attributed to the fact that race and ethnicity are markers for a manifold of underlying risk factors that impact health-including, but not limited to, socioeconomic status, access to health care, and increased exposure to the virus due to occupation (e.g., frontline, essential, and critical infrastructure workers) (Mundasad, 2020). 
Granted, parents have been adapting and solving problems forever. The novel aspects of contemporary issues are not bringing change to the ways that risk and resilience operate; rather, it is in the pervasiveness and the degree to which people across global contexts have become aware of and engaged in monitoring and responding to risk. Because these concerns pertain to broad segments of the population, considerations of risk and resilience have gained greater priority across boundaries of race, class, and culture. In addition, the strength of public warnings, the proliferation of media reports, and the volatility of both health and racial risks have elevated concerns of impending risk and necessary cautions to levels beyond the experience of current generations.

Risk, no matter the type (e.g., for becoming sick, for either perpetuating or experiencing racial discrimination, for mental health problems, and for less than optimal child development outcomes), is nonetheless dependent on a number of individual and contextual factors (e.g., work demands, presence of children and where they are in the life course, family structure, neighborhood population density, caregiving responsibilities, chronic health problems, and so on).

A majority of the issues that parents face due to the pandemic and racism, as well as the actions they may take to deal with them, are shared by fathers and mothers. Fathering and mothering occur in multiple contexts, each representing unique challenges and benefits. For example, biological fathers in stable relationships with an adult partner have different resources and challenges than stepfathers or social fathers who may or may not be residing with their children. Recent research reported by the Pew Research Center (Kramer, 2019) concludes that the USA has the world's highest rate of children living in single-parent households. Roughly one-quarter of all US fathers of minor children do not live with at least some of those children, and for many men, fathering extends beyond a single home (Monte, 2019). There are over 2.6 million father-only families in the USA, representing men having no partner to share childcare during the pandemic (Livingston, 2013). Even in two adult households, internationally, reports have emerged indicating increased marital or inter-partner conflict associated with elevated stress levels during the pandemic (e.g., Australian Red Cross, 2020). Clearly, each family has its own constellation of risk factors, individual characteristics, and contexts of development.

Yet, fathers and mothers often manifest unique differences in parenting styles and roles despite sharing convergent goals (Palkovitz et al., 2014). Because the intersections of race, class, and culture along with personal characteristics and resources determine the ways that individual fathers experience and manage risk and resilience in personally distinct ways, our title emphasizes the faces of individual fathers and their family members as they navigate the complexity of their unique relationships and circumstances. Specifically, as individual fathers utilize their executive functions to monitor, evaluate, plan, and implement their management of risk and resilience, they must face the unique circumstances of each of their children's developmental and situational resources. As they formulate their assessments and concerns with each of their children, the quality of their relationship with individual children develops as expressions of caring and restrictions on activity are articulated and experienced and fathers' resources are withheld or deployed.

\section{Changing Nature of Perceived Risk}

Fathers and their families face many practical decisions on a daily basis that cause them to assess the perceived risk associated with the pandemic and racism, to manage it, and to communicate about it to their partners and children. Yet, the risks and resources associated with the pandemic and racism are not static. They are constantly changing as new trends in infection rates and hot spots emerge, new understandings about preventative practices (e.g., wearing masks) are communicated by public health experts, and new threats and altercations occur between people in different racial groups and social addresses. Such reflections have brought new awareness and levels of discussion and debate to these issues. While it appears that there are widespread divides between people of different political leanings, educational levels, and social addresses, less is known about differences in perceptions of parents and their children based on discrepant developmental levels and family roles. Family "standard operating procedures" around school, work, and social life have been rapidly transformed by changes in policies and practices - some mandated by governments, and some enacted by individual families seeking to make sound decisions regarding personal and family safety, health, and wellbeing.

The recent and rapid changes in the contexts of family life have brought greater awareness to the reality that we are immersed, as families, in a swirling ocean of changing conditions that bring simultaneous availability of risk and opportunity. Though this has always been true, the current sentiment is that the tide is currently changing at a faster rate and at a broader scope and greater level than is typical. Neighborhood risk, local and state governments changing policies to attempt to manage risk, sector-wide and national economic changes, and global risks have taken on greater significance, or alternatively, created greater awareness of significance, in family life.

\section{Interdependence of Risks With Others In and Outside of the Family}

Contemporary events have highlighted the enduring fact that not all families have the same risk profiles. Yet, the current 
confluence of circumstances has also crystallized awareness that both within families and outside of households, the choices of others, as well as the lack of choices available to them, put each of us at risk within our families and households. That is, a vast system of factors influence individual family risk profiles. For example, if you are an essential worker, who is frequently exposed to people who may be carriers of Covid-19, your decisions and behaviors change the degree of risk my personal interactions with you pose to me and my loved ones. For example, a cashier in a neighborhood convenience store recently voiced their concern because some customers refused to wear masks, despite clear signage on the door. The cashier, whose income was essential to support family food and housing budgets, lived with their aged mother (who had a heart condition) and father (who had respiratory issues). This worker feared that customers' refusal to wear masks put their parents' lives at risk while they earned necessary wages. Considerations such as these have re-framed some common understandings of risk and resilience to be more systemic and interpersonally interdependent than had been widely appreciated in the recent past.

\section{Sources of Risk}

The circumstances of the pandemic and racial tensions have meant that families must appraise and manage risks in various, and sometimes competing, domains of their lives at the same time. For example, practical decision making has left adults considering the risks and benefits of economic mandates to open businesses and to return to forms and places of employment when weighed against the risks of contracting illness and placing their family at long-term risk, should they be incapacitated or die or infect others as a result. Whether they decide to leave their homes to go to work or to forego economic opportunities, either decision brings the reality of different risks into the lives of their family members. The affordances and demands of different job responsibilities and economic realities have yielded broadened awareness regarding risks and resilience associated with various work contexts. For example, adults who have the opportunity to telecommute are in a different position than those who are direct service providers or front-line essential workers, encountering greater exposure to extrafamilial contacts.

Families have had to evaluate the risk of various jobs to provide a living wage for their children and their families. Healthcare providers, police officers and first responders, military personnel, teachers, professional athletes, and essential workers in various professions such as retail, transportation, and hospitality industries have needed to weigh the risks and rewards of maintaining their employment in comparison to foregoing income or searching for new wage-earning opportunities in the face of economic downturns.
The policies set by school districts or universities in deciding to open their doors to students or to require online learning from home raise new and practically demanding challenges for parents thinking through how to educate their children while protecting them from unnecessary risks of infection. These practical realities of coordinating with schools/ childcare bring new or nuanced understandings to workfamily spillover. In regard to assisting children with online learning, some mothers and fathers, for the very first time, had to increase their direct engagement with their children in the role of teacher. Doing so at a quality level, while maintaining productivity at work, requires that people and their support networks tap into a range of resources to exhibit resilience. As infection rates have fluctuated and school districts and colleges and universities have changed the availability of educational delivery models, families have needed to assess, articulate, and negotiate their comfort levels with in-person versus online education and cost-benefit analyses that cut across multiple roles, domains, and contexts.

In more basic decision making, families are making judgments about the relative risks of allowing their children to interact with other children or family members indoors, outdoors, physically distanced, or without distancing, masked or not, within or across racial categories, and so forth. Their roles as protectors of their children have been tried in new daily contexts.

\section{Developmental and Gender Considerations}

Thinking about how to protect children from invisible dangers such as viral droplets and racial prejudice takes adult vision and understanding of children's developmental limitations and capabilities. Parents have daily opportunities to assess their children's theory of mind while formulating and enacting protective strategies. Such considerations have highlighted differences in parents' and children's developmental maturity and the importance of consistent behavioral follow-through and adult monitoring to maintain safe margins. Parents vary in their ability to understand the developmental needs of their children. Yet, understanding the developmental needs of children during a pandemic and heightened racial tensions is uncharted territory for most parents. Will my child suffer from not having face-to-face social interaction with peers? Will my child recover from the lack of cognitive stimulation resulting from not going to school? How do I know if I am providing the right learning opportunities for my child? How do I address justice and privilege at an appropriate level? In "normal" times, fulfilling the developmental needs of children takes place within well-established social structures. Parents know that preschool programs are designed to prepare children for school. They know that schools will help socialize children to learn how to cooperate and work with others. The absence or 
diluting of these structures leaves parents with the task of having to figure out how best to meet children's many needs that go beyond familiar boundaries of family life.

We know some things about how the pandemic and systemic racism are playing out in families with children. Mothers and fathers have had to make many changes to keep the family safe and to ensure that basic needs are met. Mothers and fathers have had to take turns caring for children while the other parent works. Mothers and fathers have had to become teachers. However, we do not know the following: are gendered behaviors changing as a result of the pandemic? Or, are fathers and mothers basically re-creating gendered behaviors that were in place before the pandemic? For example, are fathers stepping up to provide increased levels and qualities of care in all aspects of meeting children's needs? Are they relying on mothers to learn how to become teachers, or are they taking on these responsibilities? Are fathers finding it more difficult than mothers to adapt to changes in family life because of gender attitudes and norms?

\section{Challenges to Managing Risk That Are Unique to Fathers}

Parenting places individuals into a different developmental context for considering risk and resilience in comparison to caring for the self or a partner. As one becomes other-oriented, and perhaps, to the degree that one becomes invested in the wellbeing of others, allocentric people change and manage their risk profiles differently as a result (Palkovitz, 2002). They recognize that their decisions and their behaviors have both major and nuanced influences that ripple across time and generations and affect the wellbeing of their partners, their parents, and their children. While the tasks associated with managing risk and resources take on new meaning for both women and men when they become parents, fathers may experience some unique challenges when faced with a pandemic or racism.

Gender role strain is one such challenge that may affect fathers differently than mothers. Pleck (1989) suggested that gender role norms frequently provide challenges for men, both when they conform to them and when they do not. Despite the trend for both married or cohabiting fathers and mothers to work outside of the home and to increasingly share responsibilities for child care, the male provider role has remained one of the most salient masculine identities in American society. While the male provider role has seldom been readily attainable for poor men in racial and ethnic minority families, it is nonetheless an important component of those men's identities as well. The pandemic and the pervasive effects of racism in America exacerbate the strain that fathers experience in fulfilling the provider role. Fathers who had never before been out of work, or feared the risks to their family's health of going to work, or confronting perceived racial injustices on the job, are now faced with the reality that they may not be able to provide for their families without engaging in significant risktaking behaviors. Some fathers who are fortunate enough to be able to work from home during the pandemic must also deal with the strain of having to balance employment and child care responsibilities with their partners who themselves must work at home. It has not been uncommon to hear both fathers and mothers say that there is just not enough time in the day to do everything that is expected of them as workers and parents during these difficult times. Fathers for whom the provider role is central to their identities may find these circumstances particularly stressful.

Pleck (1989) has also suggested that men can experience dysfunctional strain when they overconform to masculine gender roles. Masculine ideals sometimes promote "toughness" as a desirable trait. Toughness manifests in various ways. It may mean either confronting or enduring prejudicial treatment for the good of your family. In the context of one's health, some men avoid going to the doctor when they are sick or injured, they go to work when they feel ill, or they do not follow through with their doctor's treatment recommendations. Some men go to work when they are ill because employers do not provide sick leave benefits and threaten to fire them for not showing up. Overconforming to masculine norms also may take place in men's use of face masks. A recent Gallop Poll found that $63 \%$ of men versus $81 \%$ of women always or very often use face masks when they are outside of the home (Brennan, 2020, July 13). Overconforming to masculine norms can lead to dysfunctional strain and then to negative outcomes for men. According to the Center for Disease Control, 54\% of all Covid-19 deaths were among men compared with $46 \%$ of women as of August 12, 2020. Researchers have suggested that the negative outcomes for men are attributed to a combination of genetics and immunology as well as far higher levels of alcohol consumption and smoking (Bwire, 2020), behaviors that are associated with overconforming to masculine norms.

The awareness and assessment of risk vary greatly by personality, upbringing, and perceived locus of control and agency. For several decades, research has documented that engaged fathers, in comparison to age-matched peers without children or unengaged fathers, voice different profiles of awareness toward and consequences of risks to themselves, and consequently, for their families. Simply stated, engaged fathers voice increased awareness of systemic risk factors at various levels of operation and engage in adaptive strategies to avoid, minimize, or manage them. Anecdotally, we have heard fathers speak about the risks of children falling behind from not being in school, while at the same time, they never thought they would have to become their child's teacher when schools went virtual. For engaged fathers, assessing and responding to perceived risk is different from risk 
management for any other group of people because the fathering role is distinct from any other role. Though protection is often recognized as an important aspect of paternal roles, individual men have ways that they envision and enact multiple facets of fathering roles that are somewhat unique both to them and to each of their children. When they face the consequences of various risks, they respond in unique ways in each relationship. It is neither more nor less important nor individualistic than any mother's response ... it is simply different because fathering and mothering roles and relationships, though convergent in many spheres, are distinct in some ways.

\section{Resilience in the Context of Covid-19 and Systemic Racism}

What does it mean to be resilient in current conditions? Fathers who can be more flexible in family roles may be more resilient. Resilience, emerging from risky circumstances with demonstrated wellbeing, suggests that there are psychological or social factors that protect individuals from being negatively affected by adversity or personal challenges. Many of the psychological and social factors that are likely to protect fathers from the stresses associated with the pandemic and racism are no different from those that men utilize under more normal circumstances. For example, fathers who have personality characteristics such as high conscientiousness are likely to take more precautions to protect their family from the risks of contracting Covid-19 or encountering particularly dangerous events or neighborhoods. We suggest here that there are a number of resources that stand out as unique ways in which fathers protect themselves and their families at this time. Each resource has associated risks.

Social protective factors such as being able to telecommute for work provide residential fathers with a different range of opportunities to remain engaged with their children than nonresidential fathers who, either due to digital limitations or developmental status of their children, are less able to maintain frequent high-quality father-child interactions. Similarly, recent discussions regarding systemic and/or structural racism have begun to illuminate differential lived experiences for Black and Brown men and their families in comparison to Asian-American and Caucasian fathers.

Fathers with access to and knowledge of internet technology are likely to benefit from many resources that other fathers may not be able to use. Fathers with access to Web conferencing software or Facetime can stay in touch with extended family and friends in ways that may be more meaningful than through simple use of email on a cellphone. These fathers can also help children by assisting them to set up Web-based play time among friends and peers. The infrastructure for communication and product delivery through online resources did not exist until recently, highlighting the role of historical time in navigating risk. Positive interpersonal relationships and communication skills help us talk through and trust that family members are doing the right thing now or to confirm that greater precautions or new strategies are needed. These are practical and everyday examples of how risk and resilience have become a lived experience for all—not limited to certain populations.

While modern computer technology can be an important resource in times like these, it can also be a source of much stress. These affordances are not uniformly available across social and physical addresses. Many families do not have access to high-speed broadband internet service. The capacity to stay connected with others may be greatly diminished with slow internet or inadequate service. Fathers working from home may also experience stress from having to share devices and bandwidth with others in the household. Such forms of work-family stress may have occurred infrequently before the pandemic. The proliferation of information and misinformation, and the ability to distinguish between them, presents a different set of risks and resilience.

Another extremely important resource is social support from extended family members. Public health experts have strongly recommended that families limit their face-to-face contact to a small number of individuals as a means to minimize the spread of the virus. Limited access to others means far less reciprocal in-person social support. Fathers and mothers who relied on neighbors or babysitters to go shopping or engage in leisure activities now must curtail those activities. In many instances, parents have limited their face-to-face contact only to extended family members such as grandparents. A small number of family members interacting with each other can help ensure limited virus exposure. Yet, some fathers and mothers do not have extended family members upon whom they can rely for support, either because of geographical separations or because of grandparents who are aged or incapacitated. Older extended family members can also be a source of stress because of the dangers when fathers go to work and potentially place risk on elders to contract the virus. In many regards, fathers who have personal traits of adaptability are those most able to adjust to the rapidly changing conditions, policies, and resources associated with their perceived family risks. These fathers are able to manifest masculine qualities of protection, provision, and care, demonstrating resilience in the face of multiple risks.

We stated above that the experience of risk is distinctive for fathers who experience different intersections of race, class, culture, age of child, status of fathering context (e.g., residential versus non-resident), employment, neighborhood, and so on. As articulated in the resource theory of fathering (Palkovitz \& Hull, 2018), men in different social addresses, developmental statuses, and situational confluences have vastly different bio-psycho-social-spiritual resources and differential ability to deploy and manage their resources. Where margins are thin, risk has the potential to bring greater devastation to men's ability to father in the manner that they desire to. 
Men with an abundance of resources tend to weather risks more resiliently. For example, being a residential father, having a job where you can telecommute, having positive and proximate relationships with grandparents or other family members who are healthy and able to provide childcare, suburban or rural housing with secure outdoor space, and access to internet communication resources and online shopping have brought greater coping and risk management to families in comparison to those who lack those resources.

\section{Conclusions}

As fathers navigate their daily lives in the midst of their relationships with their partners and their children, complex interactions of personal, interpersonal, and contextual resources shape their lived experiences. In times of rapid and widespread immersion into unprecedented changes, the central principles of risk and resilience continue to operate across the contexts of health, racism, and their intersections. Whether fathers perceive themselves and their families to be doing well or to lack wellbeing, utilizing their executive functions to monitor risks, deploy resources, and maintain wellbeing yields optimal outcomes given the challenges they face with what they have on hand.

\section{References}

American Medical Association. (2020). Covid FAQs: Health equity in a pandemic. https://www.ama-assn.org/delivering-care/health-equity/
Covid-faqs-health-equity-pandemic ? g clid= Cj0KCQjw59n8BRD2ARIsAAmgPmJjTj9VvfTOTN mH8k01Ux0H3yBYmk8UVpfdBqHZuEA1Y6VLQjAZfMa Au4lEALw_wcB

Australian Red Cross. (2020). Defusing family tension and conflict during the Covid-19 pandemic. https://www.redcross.org.au/stories/ covid-19/covid-19-and-family-conflict

Brennan, M. (2020). Americans' face mask usage varies greatly by demographics. Gallop Poll. https://news.gallup.com/poll/315590/ americans-face-mask-usage-varies-greatly-demographics.aspx

Bwire, G. M. (2020). Coronavirus: Why men are more vulnerable to Covid than women? SN Comprehensive Clinical Medicine, 1-3. Advance online publication. https://doi.org/10.1007/s42399-02000341-w.

Kramer, S. (2019). US has world's highest rate of children living in single parent households. https://www.pewresearch.org/fact-tank/2019/12/ 12/u-s-children-more-likely-than-children-in-other-countries-tolive-with-just-one-parent/

Livingston, G. (2013). The rise of single fathers. Pew Research Center. https://www.pewsocialtrends.org/2013/07/02/the-rise-of-singlefathers/\#fn-17500-1

Monte, L. (2019). Fathering across households. Houston, Texas: Population Association of America https://www.census.gov/ content/dam/Census/library/working-papers/2019/demo/sehsdwp2019-07.pdf.

Mundasad, S. (2020). Black people 'twice as likely to catch coronavirus'. BBC News. https://bbc.com/news/health-54907473.

Palkovitz, R. (2002). Involved fathering and men's adult development: Provisional balances. NJ: Lawrence Erlbaum Associates.

Palkovitz, R., \& Hull, J. (2018). Toward a resource theory of fathering. Journal of Family, Toward a Resource Theory of Fathering Theory \& Review, 10(1), 181-198.

Palkovitz, R., Trask, B. S., \& Adamsons, K. (2014). Essential differences in the meaning and processes of mothering and fathering: Family systems, feminist and qualitative perspectives. Journal of Family Theory and Review, 6, 406-420.

Pleck, J. H. (1989). The work-family role system. In L. Richardson \& V. Taylor (Eds.), Feminist frontiers II (pp. 161-169). New York: Random House. 